\title{
Diversidade e dinâmica populacional de ácaros em pomar cítrico
}

\author{
Marcos Zatti da Silva ( $\left.{ }^{1 *}\right)$; Mário Eidi Sato ('); Carlos Amadeu Leite de Oliveira ${ }^{2}$ ) \\ (') Instituto Biológico, Caixa Postal 70, 13001-970 Campinas (SP), Brasil. \\ (2) UNESP, Faculdade de Ciências Agrárias e Veterinárias, Departamento de Fitossanidade, Via de acesso Donato Castellane s/n, \\ 14884-900 Jaboticabal (SP), Brasil. \\ (*) Autor correspondente: makdsil@ig.com.br
}

Recebido: 13/jul/2011; Aceito: 7/fev./2012

\begin{abstract}
Resumo
As plantas de citros hospedam diversas espécies de ácaros que causam sérios prejuízos à produção e qualidade de frutos no Brasil. Esta pesquisa teve por objetivo estudar a diversidade de ácaros e a dinâmica populacional das principais espécies de ácaros em pomar de citros, Citrus sinensis (L.) Osbeck, localizado no município de Descalvado, Estado de São Paulo. Foram realizadas 14 avaliações em um período de 12 meses, de fevereiro de 2007 a fevereiro de 2008. Em cada avaliação, foram coletadas dez folhas e cinco frutos na parte interna de cada uma das 40 plantas demarcadas no pomar. Foram encontradas 34 espécies de ácaros, distribuídas em 17 famílias. As espécies mais abundantes foram: Phyllocoptruta oleivora (Ashmed) (Eriophyidae), Panonychus citri (McGregor) (Tetranychidae), Brevipalpus phoenicis (Geijskes) (Tenuipalpidae) e Fungitarsonemus sp. (Tarsonemidae). Entre os ácaros predadores, a família Phytoseiidae foi a de maior riqueza (oito espécies) e abundância (1.072 indivíduos). A espécie predominante foi Euseius concordis (Chant), correspondendo a 98,3\% dos ácaros desta família. Foram observadas correlações significativas entre densidades populacionais de E. concordis e dos ácaros fitófagos P. citri, B. phoenicis e P. oleivora. Também foram observadas correlações significativas entre densidades populacionais desses ácaros e fatores meteorológicos como temperatura e precipitação pluvial. Os resultados indicam que E. concordis atua como inimigo natural de P. citri, B. phoenicis e P. oleivora no pomar cítrico estudado.
\end{abstract}

Palavras-chave: ácaros fitófagos, ácaros predadores, Citrus sinensis, fauna acarina.

\section{Diversity and population dynamics of mites in citrus orchard}

\section{Abstract}

The citrus plants are hosts of several species of mites, which cause severe damage to production and quality of fruits in Brazil. The objective of this research was to study the diversity of mites and population dynamics of the main mite species in a citrus orchard, Citrus sinensis (L.) Osbeck, in Descalvado County, State of São Paulo, Brazil. Fourteen evaluations were conducted over a period of 12 months, from February 2007 to February 2008. At each assessment, ten leaves and five fruits were collected from the inner part of each citrus canopy, from a total of 40 marked plants. Thirty four mite species were found, which were distributed into 17 families. The most abundant species were: Phyllocoptruta oleivora (Ashmed) (Eriophyidae), Panonychus citri (McGregor) (Tetranychidae), Brevipalpus phoenicis (Geijskes) (Tenuipalpidae) and Fungitarsonemus sp. (Tarsonemidae). Among the predators, the Phytoseiidae family presented the highest richness (eight species) and the highest abundance (1,072 individuals). Euseius concordis (Chant) was the predominant species, corresponding to 98.3\% of the mites of this family. Significant correlations were observed between the population densities of E. concordis and of the phytophagous mites P. citri, B. phoenicis and P. oleivora. Significant correlations were also observed between population densities of these mites and meteorological factors such as temperature and precipitation. The results indicate that E. concordis acts as a natural enemy of P. citri, B. phoenicis and P. oleivora in the citrus orchard.

Key words: phytophagous mites, predatory mites, Citrus sinensis, mite fauna. 


\section{INTRODUÇÃO}

A cultura de citros é hospedeira de várias espécies de ácaros, algumas das quais assumem a condição de praga de considerável importância econômica. Algumas espécies são predadoras, alimentando-se de ácaros fitófagos, insetos e pólen (Gravena et al., 1999).

As espécies mais comuns de ácaros fitófagos associadas às plantas cítricas pertencem às famílias Eriophyidae, Tenuipalpidae, Tarsonemidae e Tetranychidae, sendo o ácaro-da-leprose-dos-citros Brevipalpus phoenicis (Geijskes) (Tenuipalpidae) e o ácaro-da-falsa-ferrugem-dos-citros Phyllocoptruta oleivora (Ashmead) (Eriophyidae) considerados pragas-chave (YanineK e Moraes, 1991; Moraes, 1992; Gravena et al., 1999). Outras espécies ocorrem em citros, como o ácaro-branco Polyphagotarsonemus latus (Banks) (Tarsonemidae), o ácaro-purpúreo Panonychus citri (McGregor), o ácaro-mexicano Tetranychus mexicanus (McGregor), o ácaro-texano Eutetranychus banksi (McGregor) (Tetranychidae), além do ácaro-verde-alaranjado Lorryia formosa (Cooreman) (Tydeidae) (Moraes e Flechtmann, 2008).

Ácaros da família Phytoseiidae são considerados os mais importantes agentes reguladores de populaçôes de ácaros fitófagos (Helle e Sabelis, 1985; McMurtry e Croft, 1997). Nos pomares cítricos do Estado de São Paulo, as espécies de Phytoseiidae mais frequentes são Iphiseiodes zuluagai Denmark \& Muma, Euseius concordis (Chant) e Euseius citrifolius Denmark \& Muma (Sato et al., 1994; Raga et al., 1996).

SATO et al. (1994) observaram a presença de seis espécies de ácaros predadores da família Phytoseiidae, em pomar de laranja, em Presidente Prudente (SP), sendo as de maior incidência I. zuluagai, E. citrifolius e E. concordis, representando, respectivamente, $47,3 \%$; $26,5 \%$ e $25,7 \%$ dos ácaros coletados. Amblyseius chiapensis DeLeon, Euseius alatus DeLeon e Typhlodromina camelliae (Chant e Shaul) representaram juntas menos de $1 \%$ do número total de ácaros coletados.

A família Stigmaeidae também possui espécies de ácaros predadores que se alimentam de ácaros-praga em citros, com destaque para os gêneros Agistemus e Zetzellia (Matioli et al., 2002).

O conhecimento da diversidade e dinâmica populacional de ácaros presentes em citros, nas diferentes regiôes do país, é fundamental para o estabelecimento de estratégias de manejo integrado de pragas em citros, visando preservar as principais espécies de inimigos naturais presentes nos pomares.

Embora tenham sido realizadas diversas pesquisas sobre ácaros em pomares cítricos no Estado de São Paulo, ainda são poucas as informaçóes sobre a diversidade e dinâmica de ácaros em citros na regiâo de Descalvado (SP). Assim, esta pesquisa teve por objetivo estudar a diversidade de ácaros e a dinâmica populacional das principais espécies de ácaros fitófagos e predadores, incluindo análises sobre interação entre espécies fitófagas e predadoras, bem como a influência de fatores climáticos na comunidade de ácaros presente em citros, no município de Descalvado (SP).

\section{MATERIAL E MÉTODOS}

O estudo foi realizado em cultivo convencional de Citrus sinensis (L.) Osbeck var. Pera, sem qualquer tratamento fitossanitário, localizado na Fazenda Santana (21059'S; 47035'W; $784 \mathrm{~m}$ ), município de Descalvado, Estado de São Paulo. As plantas estavam com, aproximadamente, quatro anos de idade, $2 \mathrm{~m}$ de altura e espaçamento de $7 \mathrm{~m}$ entre linhas e $5 \mathrm{~m}$ entre plantas.

Foram realizadas 14 avaliaçôes em um período de 12 meses (28/2/2007 a 22/2/2008), com intervalo médio entre amostragens de 3,6 semanas. Em cada avaliação foram coletados dez folhas e cinco frutos na parte interna de cada planta, em 40 plantas marcadas. As amostras foram colocadas em sacos plásticos, devidamente identificadas e acondicionadas em caixas de poliestireno expandido contendo gelo, para diminuir a atividade dos ácaros durante o transporte para o laboratório.

Em laboratório, os frutos e as folhas foram colocados, separadamente, em recipientes plásticos contendo álcool etílico a 70\%, onde permaneceram imersos por cinco minutos. Decorrido este prazo, as amostras foram levemente agitadas nesta solução para que os ácaros fossem retidos no líquido do recipiente. Em seguida, foram removidos os frutos e as folhas e a soluçấo foi passada por uma peneira com malha de $0,038 \mathrm{~mm}$, "tyler 400 ". O material retido na peneira foi transferido para um frasco de vidro com capacidade de $30 \mathrm{~mL}$ através de um funil com o auxílio de uma pisseta contendo álcool etílico a 70\%.

A triagem dos ácaros foi feita utilizando-se microscópio estereoscópico com aumento de até 60 vezes. Os ácaros foram montados em lâminas de microscopia, em meio de Hoyer (Flechtmann, 1989), com exceção dos eriofí́deos, que foram montados em meio Berlese modificado (Amrine e Manso, 1996).

Com relação aos eriofídeos, aproximadamente 1\% (2.100 exemplares) dos ácaros foram montados e identificados, haja vista a grande quantidade de exemplares.

As lâminas foram mantidas em estufa a $45-55^{\circ} \mathrm{C}$ por cerca de dez dias para a fixação e clarificação dos espécimes e secagem do meio. Posteriormente, foi feita a lutagem das bordas das lamínulas. As identificaçôes dos ácaros foram realizadas com o auxílio de um microscópio óptico com contraste de fases.

A análise de regressão linear foi utilizada para estimar a associação entre as densidades populacionais das espécies de ácaros mais abundantes em folhas e frutos, e os fatores meteorológicos: temperatura média $\left({ }^{\circ} \mathrm{C}\right)$ e precipitação pluvial (média semanal, em mm).

Para a observação da possível influência de ácaros predadores (Phytoseiidae) sobre as principais espécies de ácaros 
fitófagos e de hábitos alimentares variáveis, foi utilizada análise de correlação, com estimativa do coeficiente de correlação de Pearson.

Para fins de análise estatística, o experimento foi dividido em quatro repetiçóes, com 10 plantas por repetição, para cada data de amostragem. Os dados de abundância, temperatura e precipitação pluvial foram transformados em $\sqrt{\mathrm{x}+0,5}$. As análises foram realizadas utilizando-se o programa BioEstat 5.0 (Ayres et al., 2007).

\section{RESULTADOS E DISCUSSÃO}

Foram coletadas em Descalvado (SP), 34 espécies de ácaros, distribuídas em 17 famílias (Tabela 1). Entre os ácaros fitófagos, o eriofiídeo P. oleivora se destacou como o mais abundante, tendo sido coletados 211.501 espécimes. Os ácaros $P$. citri e $B$. phoenicis, respectivamente, com 3.542 e 2.906 exemplares, foram a segunda e a terceira espécie mais abundante (Tabela 1). Outras espécies de ácaros fitófagos (Tetranychidae) encontradas foram E. banksi (35 espécimes), Tetranychus sp. (42) e Allonychus sp. (2) (Tabela 1). Para os dois últimos gêneros, não foi possível a identificação específica devido à ausência de machos nas amostras (Tabela 1).

Dentre as espécies de maior frequência em citros no Brasil, B. phoenicis se destaca pela sua grande importância para a cultura, devido à transmissáo do vírus-da-leprose-dos-citros, que provoca lesóes nos frutos, ramos e folhas, com queda prematura de frutos, desfolhamento e morte de ramos (Rodrigues et al., 2003).

Dentre os ácaros de hábito alimentar variado observados no pomar cítrico de Descalvado, destacaram-se as espécies Fungitarsonemus sp. (Tarsonemidae) e Parapronematus acaciae Baker (Iolinidae), respectivamente, com 2.604 e 209 espécimes (Tabela 1).

Estudos em laboratório com $P$. acaciae mostraram que o referido ácaro não se alimentava de $P$. oleivora ou $P$. citri, sendo possível criá-lo por quatro geraçōes sobre fungos (Penicillium digitatum Sacc.; Colletotrichum gloesporioides Penzig), indicando que $P$. acaciae não representava um inimigo natural promissor para os ácaros fitófagos presentes em pomares cítricos (Mccoy et al., 1969).

Além de citros, Fungitarsonemus sp. e P. acaciae têm sido observados em outras culturas no Brasil, como a do cafeeiro (Spongoski et al., 2005; Mineiro et al., 2010).

Dentre os ácaros predadores observados no pomar cítrico de Descalvado, a família Phytoseiidae destacou-se pela a maior abundância (1.074 indivíduos) e a maior riqueza (oito espécies) (Tabela 1). De acordo com YanineK e Moraes (1991), dentre os ácaros predadores verificados em citros, a maioria pertence à família Phytoseiidae.

Os fitoseídeos registrados foram: E. concordis (1.054 espécimes), E. citrifolius (1), I. zuluagai (12), Metaseiulus sp. (1), Phytoseiulus macropilis (Banks) (2), Neoseiulus sp. (1), Typhlodromus transvaalensis (Nesbit) (2) e
Typhlodromus sp. (1) (Tabela 1). Euseius concordis foi a espécie predominante, correspondendo a 99,2\% dos ácaros fitoseídeos presentes em folhas e 93,2\% dos fitoseídeos registrados em frutos. A maioria $(85,1 \%)$ dos espécimes de E. concordis foi observada em folhas (Tabela 1).

Os ácaros predadores da família Phytoseiidae alimentam-se principalmente de ácaros, mas podem também se alimentar de pequenos insetos, nematóides, fungos, pólen e exsudatos de plantas. Algumas espécies como as do gênero Phytoseiulus, classificadas como predadores do Tipo I (CROFT et al., 2004), são especializadas em atacar ácaros que produzem teia, principalmente Tetranychus spp. Espécies como as dos gêneros Galendromus e Metaseiulus (Tipo II) alimentam-se principalmente de ácaros da família Tetranychidae, mas não se restringem a Tetranychus spp. Ácaros dos gêneros Typhlodromus (Tipo III) e Euseius (Tipo IV) são considerados generalistas, alimentando-se de diversas espécies de ácaros, incluindo em sua dieta, pólen e exsudatos de plantas (Grafton-Cardwell e Ouyang, 1996; McMutry e Croft, 1997; Croft et al. 2004).

Nos pomares cítricos no Estado de São Paulo, as espécies de Phytoseiidae observadas com maior frequência têm sido I. zuluagai, E. concordis e E. citrifolius (SATO et al., 1994; Raga et al., 1996; Albuquerque e Moraes, 2008).

ReIs et al. (2000) verificaram que $I$. zuluagai e $E$. alatus foram as espécies mais frequentes em folhas de laranjeira 'Valência', seguidas de Amblyseius compositus (Denmark \& Muma), Amblyseius herbicolus (Chant) e P. macropilis, em pomar de Lavras (MG).

A família Stigmaeidae pode ser considerada como o segundo grupo de maior importância no controle biológico de ácaros pragas na agricultura. Em estudos realizados nos municípios de Limeira, Araraquara, Jaboticabal, Itápolis, Bebedouro e Olímpia, Estado de São Paulo, Matioli et al. (2002) observaram que as espécies de estigmaeídeos mais frequentes foram $A$. brasiliensis, Agistemus floridanus Gonzales e Zetzellia malvinae Matioli, Ueckermann e Oliveira, sendo A. brasiliensis a espécie mais abundante, representando $85 \%$ do total de estigmeídeos coletados em citros.

A pequena incidência de ácaros estigmeídeos, com apenas nove espécimes observados no pomar cítrico de Descalvado, pode estar associada à elevada densidade populacional de ácaros predadores da família Phytoseiidae, principalmente $E$. concordis, que atingiu a uma média de 1,5 ácaro por folha, nos períodos mais favoráveis do ano (janeiro e fevereiro). SATo et al. (2001) observaram uma relação de antagonismo entre ácaros das famílias Phytoseiidae e Stigmaeidae, em pomar cítrico de Presidente Prudente (SP), onde foi verificado crescimento populacional de estigmeídeos após a eliminação de fitoseídeos com uso de inseticidas. Com o retorno da população de fitoseídeos, observou-se tendência de diminuição dos ácaros estigmeídeos. Esse antagonismo pode estar associado à competição por alimentos e predação mútua, 
Tabela 1. Ácaros coletados em frutos e folhas de laranjeira (Citrus sinensis) em Descalvado (SP), no período de 28/2/2007 a 22/2/2008

\begin{tabular}{|c|c|c|c|c|}
\hline Espécie & Fruto & Folha & Total & Hábito alimentar \\
\hline \multicolumn{5}{|l|}{ PROSTIGMATA } \\
\hline \multicolumn{5}{|l|}{ Cheyletidae } \\
\hline Chletogenes sp. & 2 & - & 2 & Predador \\
\hline \multicolumn{5}{|l|}{ Cunaxidae } \\
\hline Coleobonzia sp. & 3 & 11 & 14 & Predador \\
\hline Cunaxidae não identificado & 1 & 2 & 3 & Predador \\
\hline \multicolumn{5}{|l|}{ Eriophyidae } \\
\hline Phyllocoptruta oleivora & 113.211 & 98.290 & 211.501 & Fitófago \\
\hline \multicolumn{5}{|l|}{ Eupalopsellidae } \\
\hline Exothorhis sp. & 3 & 1 & 4 & Predador \\
\hline \multicolumn{5}{|l|}{ Raphignatidae } \\
\hline Raphignatus sp. & - & 1 & 1 & Predador \\
\hline \multicolumn{5}{|l|}{ Stigmaeidae } \\
\hline Agistemus brasiliensis & 2 & 7 & 9 & Predador \\
\hline \multicolumn{5}{|l|}{ Tarsonemidae } \\
\hline Daidalotarsonemus sp. & 11 & 10 & 26 & Variado* \\
\hline Fungitarsonemus sp. & 299 & 2.305 & 2.604 & Variado \\
\hline Polyphagotarsonemus latus & 40 & 38 & 78 & Fitófago \\
\hline Tarsonemus sp. & 96 & 337 & 433 & Variado \\
\hline \multicolumn{5}{|l|}{ Tenuipalpidae } \\
\hline Brevipalpus phoenicis & 2.468 & 438 & 2.906 & Fitófago \\
\hline \multicolumn{5}{|l|}{ Tetranychidae } \\
\hline Panonychus citri & 1.026 & 2.516 & 3.542 & Fitófago \\
\hline Eutetranychus banksi & 15 & 20 & 35 & Fitófago \\
\hline Tetranychus sp. & 25 & 17 & 42 & Fitófago \\
\hline Allonychus sp. & 1 & 1 & 2 & Fitófago \\
\hline \multicolumn{5}{|l|}{ Iolinidae } \\
\hline Homeopronematus sp. & 23 & 29 & 52 & Variado \\
\hline Parapronematus acaciae & 115 & 94 & 209 & Variado \\
\hline \multicolumn{5}{|l|}{ Tydeidae } \\
\hline Lorryia formosa & 4 & 5 & 9 & Variado \\
\hline \multicolumn{5}{|l|}{ MESOSTIGMATA } \\
\hline \multicolumn{5}{|l|}{ Ascidae } \\
\hline Lasioseius sp. & 1 & - & 1 & Predador \\
\hline \multicolumn{5}{|l|}{ Laelapidae } \\
\hline Laelapidae não identificado & 1 & - & 1 & Predador \\
\hline \multicolumn{5}{|l|}{ Phytoseiidae } \\
\hline Euseius concordis & 157 & 897 & 1.054 & Predador \\
\hline Euseius citrifolius & - & 1 & 1 & Predador \\
\hline Iphiseiodes zuluagai & 7 & 5 & 12 & Predador \\
\hline Metaseiulus sp. & 1 & - & 1 & Predador \\
\hline Neoseiulus sp. & 1 & - & 1 & Predador \\
\hline Phytoseiulus macropilis & 2 & - & 2 & Predador \\
\hline Typhlodromus transvaalensis & 2 & - & 2 & Predador \\
\hline Typhlodromus sp. & - & 1 & 1 & Predador \\
\hline \multicolumn{5}{|l|}{ ASTIGMATA } \\
\hline Acaridida não identificado & 2 & 3 & 5 & Variado \\
\hline \multicolumn{5}{|l|}{ Acaridae } \\
\hline Tyrophagus sp. & 6 & 4 & 10 & Variado \\
\hline \multicolumn{5}{|l|}{ Winterschmidtiidae } \\
\hline Saproglyphus sp. & - & 2 & 2 & Variado \\
\hline \multicolumn{5}{|l|}{ Criptostigmata } \\
\hline Oribatida não identificado & - & 5 & 5 & Variado \\
\hline
\end{tabular}

*Habito alimentar variado ou pouco conhecido. 
principalmente de ovos (SATO et al., 2001). Outros autores (Clements e Harmsen, 1992; Macrae e Croft, 1996) também mencionaram interaçóes negativas entre ácaros dessas famílias.

Outro fator que pode ter contribuído para a pequena densidade populacional de estigmeídeos é sua grande sensibilidade a diversos produtos químicos (ex.: espirodiclofeno, calda sulfocálcica, hexythiazox, etc.), comumente utilizados em citros no Estado de Sáo Paulo (Silva et al., 2009). Alguns desses produtos (ex.: espirodiclofeno) haviam sido utilizados no pomar
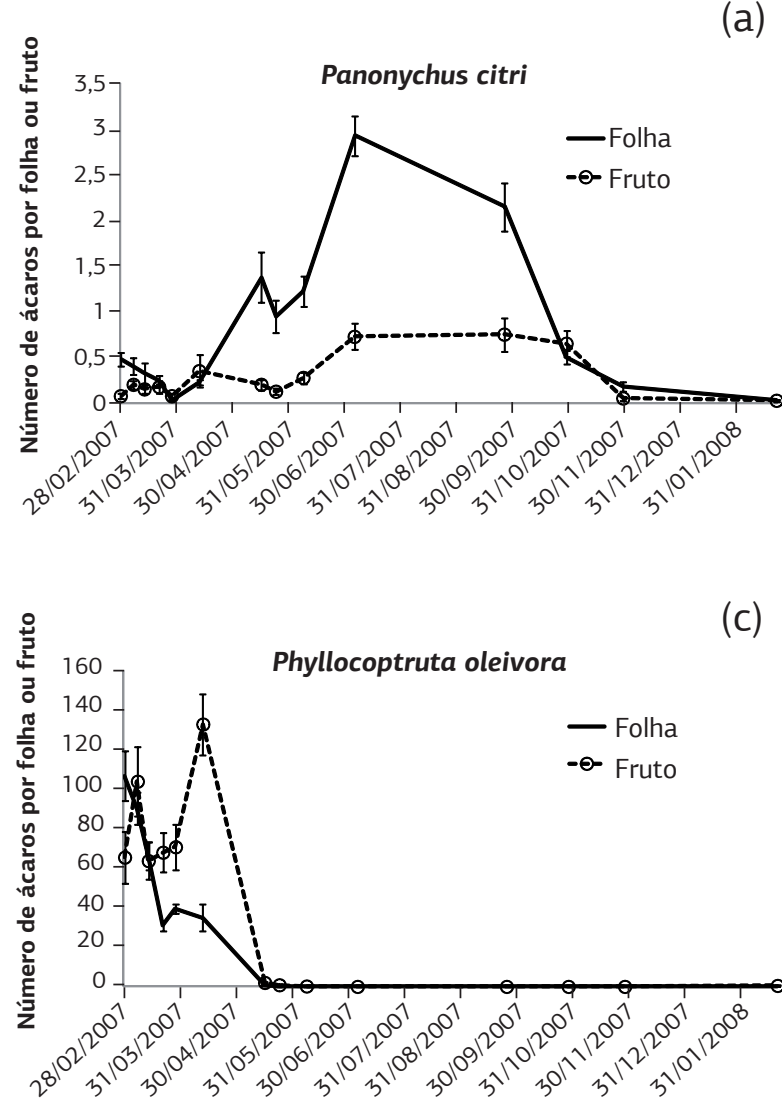

estudado, em períodos anteriores (mais de seis meses) ao início do estudo.

Com relação às densidades populacionais das principais espécies de ácaros no pomar estudado, observaram-se diferentes padrốes de flutuação populacional para as diversas espécies de ácaros. As maiores populaçóes de $E$. concordis foram observadas entre novembro e março, correspondendo aos períodos mais quentes e chuvosos do ano (Figura 1). Para essa espécie, foram observadas correlaçôes positivas e significativas $(r>0,39$; g.l. $=54 ; \mathrm{p}<0,004)$ entre as densidades populacionais do predador (em folhas) e os (a)

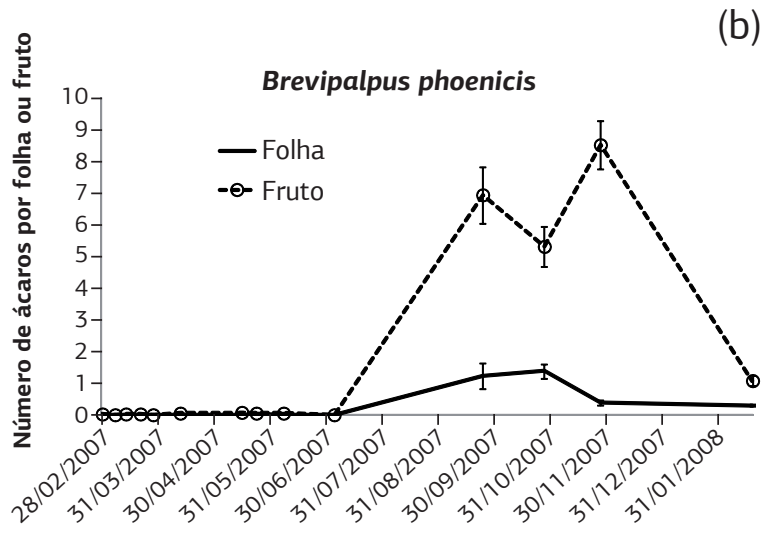

c)

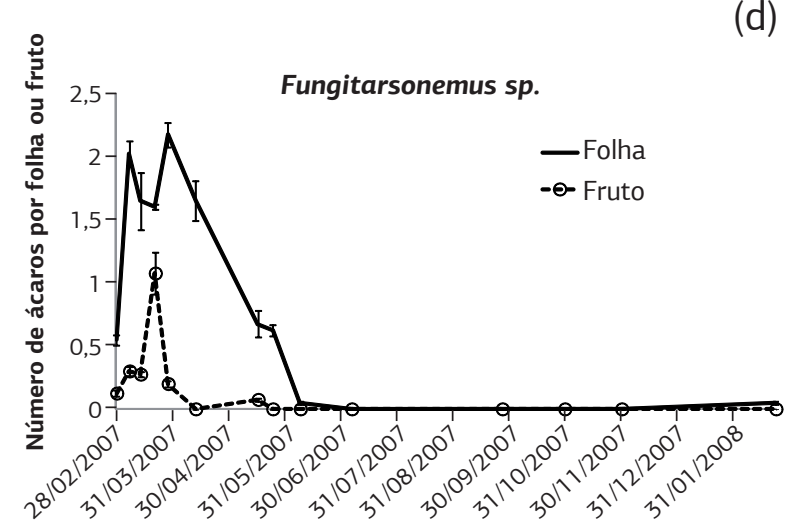

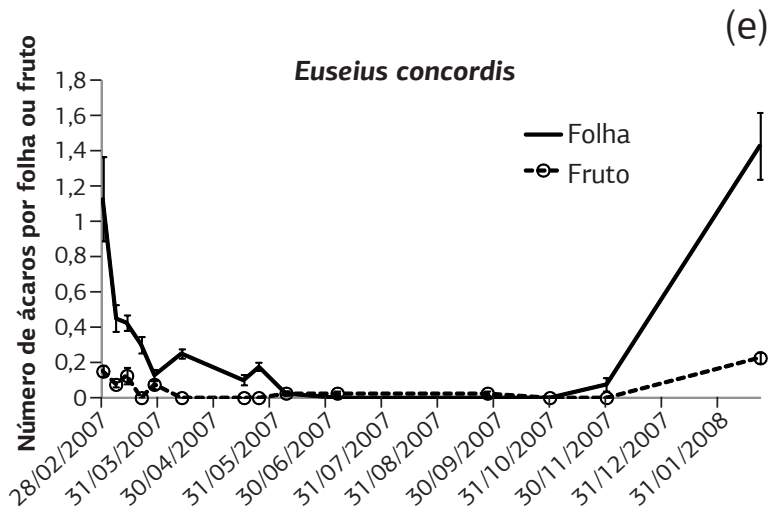

Figura 1. Flutuação populacional das espécies de ácaros mais abundantes: (a) Panonychus citri; (b) Brevipalpus phoenicis; (c) Phyllocoptruta oleivora; .(d) Fungitarsonemus sp; (e) Euseius concordis, em pomar cítrico de Descalvado (SP), no período de 28/2/2007 a 22/2/2008. 
fatores meteorológicos temperatura média e precipitação pluvial. No caso de ácaros E. concordis presentes em frutos, observou-se correlaçáo significativa $(r=0,27$; g.l. $=54$; $\mathrm{p}=0,043)$ apenas para temperatura (Tabela 2).

Esses resultados corroboram aqueles obtidos por SATO et al. (1994), que observaram maiores populaçóes de E. concordis e E. citrifolius nos meses mais quentes e chuvosos do ano, em pomar cítrico de Presidente Prudente. Resultados semelhantes também foram obtidos para E. alatus por ReIs et al. (2000), estudando a dinâmica populacional de ácaros fitoseídeos em pomar cítrico de Lavras (MG).

Correlaçôes significativas $(r>0,26$; g.l. $=54 ; \mathrm{p}<0,04)$ também foram observadas para $P$. citri e as variáveis temperatura e precipitação pluvial (Tabela 2). No caso de $P$. citri, verificaram-se correlaçôes negativas para ambas as variáveis, ou seja, condições mais quentes e chuvosas seriam desfavoráveis para o ácaro-praga. $\mathrm{O}$ maior pico populacional para essa espécie foi observado entre junho e julho.

No caso de B. phoenicis, foi observada correlação negativa entre a população do ácaro em frutos e a precipitação pluvial, indicando que os períodos secos são favoráveis à multiplicação de $B$. phoenicis. As maiores densidades populacionais da praga ocorreram entre agosto e novembro de 2007. Esses resultados corroboram os anotados por Oliverra (1986), que menciona a preferência de B. phoenicis por períodos secos do ano.

Para Fungitarsonemus sp., observaram-se correlaçóes positivas e significativas $(r>0,29$; g.l. $=54 ; \mathrm{p}<0,02)$ entre as densidades populacionais do ácaro e as variáveis temperatura e precipitação pluvial, mostrando preferência do ácaro por condições quentes e chuvosas (Tabela 2).
Com relação à interação entre as diferentes espécies de ácaros presentes em citros, observaram-se correlaçôes significativas entre as densidades populacionais de E. concordis e das três espécies de ácaros-praga (P. citri, B. phoenicis e $P$. oleivora), mostrando uma provável influência do predador sobre as três espécies de ácaros fitófagos (Tabela 3).

Para $P$. citri, verificou-se correlação negativa entre $E$. concordis presentes em folhas e ácaros $P$. citri observados em folhas $(r=-0,39 ;$ g.l. $=54 ; \mathrm{p}=0,0028)$ e frutos $(r=-0,37 ;$ g.l. $=54 ; \mathrm{p}=0,0054)$, indicando que os ácaros E. concordis poderiam afetar a densidade populacional do ácaro tetraniquídeo, com provável deslocamento dos ácaros predadores das folhas para os frutos cítricos, a fim de exercer controle biológico da praga em frutos (Tabela 3).

Embora o número de ácaros $E$. concordis em frutos tenha sido baixo ( $\leq 0,75$ ácaros/fruto), a densidade populacional de $P$. citri em frutos também foi relativamente baixa ( $\leq 3,5$ ácaros/fruto), possibilitando o controle da praga nessas estruturas.

A influência de ácaros fitoseídeos sobre populaçôes de $P$. citri também foi observada por outros autores. FADAMIRO et al. (2009) reportaram forte associação e sincronia entre Typhlodromalus peregrinus (Muma) (Acari: Phytoseiidae) e P. citri, em citros no Alabama, indicando que o predador seria importante agente de controle biológico do ácaro-praga.

Foi observada, também, correlação significativa $(r=-0,38$; g.l. $=54 ; \mathrm{p}=0,0037)$ entre as densidades populacionais de E. concordis presentes em folhas e B. phoenicis em frutos, indicando que o predador poderia atuar como controle biológico do ácaro-praga em citros, no pomar de Descalvado (Tabela 3).

Tabela 2. Relação entre o número de ácaros (Euseius concordis, Panonychus citri, Brevipalpus phoenicis, Phyllocoptruta oleivora ou Fungitarsonemus sp.) por fruto ou folha e as variáveis: temperatura média $\left({ }^{\circ} \mathrm{C}\right)$ e precipitação pluvial (média semanal) (mm). Descalvado (SP), 28/2/2007 a 22/2/2008

\begin{tabular}{lcrrrr|} 
Variável & Equação de regressão & r & \multicolumn{1}{c}{ F } & g.I. & P \\
\hline E. concordis Fo x Temp. & $y=-0,55325+0,15226 x$ & 0,4623 & 14,6807 & 1,54 & 0,0006 \\
\hline E. concordis Fr x Temp. & $y=-0,05941+0,03253 x$ & 0,2679 & 4,1748 & 1,54 & 0,0433 \\
\hline E. concordis Fo x Precip. & $y=0,07289+0,01789 x$ & 0,3929 & 9,8556 & 1,54 & 0,0031 \\
\hline E. concordis Fr x Precip. & $y=0,07257+0,00418 x$ & 0,2490 & 3,5685 & 1,54 & 0,0610 \\
\hline P. citri Fo x Temp. & $y=1,72737-0,31626 x$ & 0,6306 & 35,6544 & 1,54 & $<0,0001$ \\
\hline P. citri Fr x Temp. & $y=0,53155-0,08096 x$ & 0,2634 & 4,0273 & 1,54 & 0,0470 \\
\hline P. citri Fo x Precip. & $y=0,44461-0,04074 x$ & 0,5875 & 28,4642 & 1,54 & 0,0001 \\
\hline P. citri Fr x Precip. & $y=0,23336-0,01651 x$ & 0,3885 & 9,5982 & 1,54 & 0,0034 \\
\hline B. phoenicis Fo x Temp. & $y=0,07907+0,00984 x$ & 0,0274 & 0,0405 & 1,54 & 0,8355 \\
\hline B. phoenicis Fr x Temp. & $y=0,14566+0,02382 x$ & 0,0242 & 0,0316 & 1,54 & 0,8537 \\
\hline B. phoenicis Fo x Precip. & $y=0,44197-0,00690 x$ & 0,3340 & 6,7816 & 1,54 & 0,0115 \\
\hline B. phoenicis Fr x Precip. & $y=0,37374-0,02281 x$ & 0,1689 & 1,5858 & 1,54 & 0,2109 \\
\hline P. oleivora Fo x Temp. & $y=-10,33480+2,42805 x$ & 0,6242 & 34,4680 & 1,54 & $<0,0001$ \\
\hline P. oleivora Fr x Temp. & $y=-11,46846+2,71158 x$ & 0,5996 & 30,3116 & 1,54 & $<0,0001$ \\
\hline P. oleivora Fo x Precip. & $y=9,41953+0,56862 x$ & 0,3201 & 6,1631 & 1,54 & 0,0154 \\
\hline P. oleivora Fr x Precip. & $y=14,24599+0,73883 x$ & 0,3052 & 5,5482 & 1,54 & 0,0209 \\
\hline Fungitarsonemus sp. Fo x Temp. & $y=-0,98054+0,257456 x$ & 0,4560 & 14,1783 & 1,54 & 0,0007 \\
\hline Fungitarsonemus sp. Fr x Temp. & $y=-0,28324+0,08342 x$ & 0,2967 & 5,2115 & 1,54 & 0,0249 \\
\hline Fungitarsonemus sp. Fo x Precip. & $y=0,04270+0,03739 x$ & 0,4790 & 16,0791 & 1,54 & 0,0004 \\
\hline Fungitarsonemus sp. Fr x Precip. & $y=0,02830+0,01614 x$ & 0,4152 & 11,2494 & 1,54 & 0,0018 \\
\hline
\end{tabular}


Tabela 3. Relação entre o número de ácaros de predadores (Euseius concordis) e ácaros fitófagos (Panonychus citri, Brevipalpus phoenicis, Phyllocoptruta oleivora) e de hábito alimentar variado (Fungitarsonemus sp.), por fruto ou folha, utilizando-se análise de correlação ( $r=$ coeficiente de correlação de Pearson). Descalvado (SP), 28/2/2007 a 22/2/2008

\begin{tabular}{lccc|} 
Variável & r & g.l. & p \\
\hline E. concordis Fo x P. citri Fo & $-0,3915$ & 54 & 0,0028 \\
\hline E. concordis Fo x P. citri Fr & $-0,3668$ & 54 & 0,0054 \\
E. concordis Fr x P. citri Fr & $-0,2094$ & 54 & 0,1213 \\
\hline E. concordis Fo x E. concordis Fr & 0,4423 & 54 & 0,0006 \\
P. citri Fo x P. citri Fr & 0,4521 & 54 & 0,0005 \\
\hline E. concordis Fo x B. phoenicis Fo & $-0,1221$ & 54 & 0,37 \\
E. concordis Fo x B. phoenicis Fr & $-0,3810$ & 54 & 0,0037 \\
\hline E. concordis Fr x B. phoenicis Fr & $-0,1623$ & 54 & 0,2321 \\
B. phoenicis Fo x B. phoenicis Fr & 0,5991 & 54 & $<0,0001$ \\
\hline E. concordis Fo x P. oleivora Fo & 0,2935 & 54 & 0,0281 \\
\hline E. concordis Fo x P. oleivora Fr & 0,0956 & 54 & 0,4834 \\
\hline E. concordis Fr x P. oleivora Fr & 0,0098 & 54 & 0,943 \\
\hline P. oleivora Fo x P. oleivora Fr & 0,6074 & 54 & $<0,0001$ \\
\hline E. concordis Fo x Fungitarsonemus sp. Fo & 0,0384 & 54 & 0,7788 \\
\hline E. concordis Fo x Fungitarsonemus sp. Fr & $-0,017$ & 54 & 0,9012 \\
\hline E. concordis Fr x Fungitarsonemus sp. Fr & 0,0473 & 54 & 0,7291 \\
\hline Fungitarsonemus sp. Fo x Fungitarsonemus sp. Fr & 0,4482 & 54 & 0,0005 \\
\hline
\end{tabular}

Correlaçóes positivas e significativas $(r=0,44$; g.l. $=54$; $\mathrm{p}=0,0006)$ entre as densidades populacionais de $E$. concordis em folhas e frutos de citros, indicam provável caminhamento dos predadores de folhas para frutos e vice-versa, podendo assim atuar no controle biológico de ácaros-praga em frutos.

Estudos preliminares realizados em laboratório, no Instituto Biológico, revelam que fêmeas de E. concordis chegam a consumir 40 ovos de $B$. phoenicis por dia, com taxa de oviposição diária de quase dois ovos, confirmando o potencial de E. concordis como agente de controle biológico do ácaro-praga em citros.

Até maio de 2007, quando as densidades populacionais de E. concordis ainda se mantinham relativamente altas ( $>0,2$ ácaro predador por folha), a população de $B$. phoenicis era praticamente nula. Observou-se crescimento populacional da praga apenas quando as condiçóes climáticas (secas e frias) passaram a ser desfavoráveis ao predador, a partir do início de julho de 2007.

Embora o crescimento populacional de B. phoenicis tenha se iniciado apenas em junho de 2007, condiçóes favoráveis para seu desenvolvimento já eram observadas desde a última semana de março, com redução da precipitação pluvial para valores semanais iguais ou inferiores a $20 \mathrm{~mm}$, com predominância de semanas com precipitação entre zero e $4,5 \mathrm{~mm}$. Considerando que para $B$. phoenicis foi observada correlaçáo significativa e negativa apenas para precipitaçáo pluvial, há indício de influência de E. concordis sobre a dinâmica populacional do ácaro-praga.

Em novembro, quando houve novo aumento populacional de $E$. concordis, verificou-se nítido decréscimo populacional de B. phoenicis (Figura 1).

Considerando que a taxa de consumo de ovos de B. phoenicis por E. concordis seria de até 40 ovos por dia (dados preliminares não publicados), densidades populacionais do predador de até 1,5 ácaros por folha explicariam a reduçáo populacional de $B$. phoenicis, cujas densidades máximas não ultrapassaram 1,4 ácaros por folha $\mathrm{e}$ 6,9 ácaros por fruto.

Mineiro et al. (2008) também observaram correlaçôes significativas entre densidades populacionais de B. phoenicis e de E. concordis em cafeeiro da região de Garça, SP, indicando que $E$. concordis seria importante inimigo natural de B. phoenicis em cafeeiro, no Estado de São Paulo.

Para $P$. oleivora, observou-se correlação positiva e significativa $(r=0,29 ;$ g.l. $=54 ; \mathrm{p}=0,028)$ entre o fitoseídeo $E$. concordis e a referida praga, apenas para folhas. Apesar da correlação significativa entre o fitófago e o predador, a população de E. concordis não foi suficiente para o controle biológico efetivo de P. oleivora, permitindo grandes populaçōes da praga em condiçốes de campo, principalmente em frutos, que são os substratos preferenciais da espécie. No caso de frutos, não foi verificada nenhuma influência dos ácaros predadores sobre o ácaro-da-falsa-ferrugem (Tabela 3).

Em relação ao ácaro Fungitarsonemus sp., não foi observada nenhuma correlação significativa entre $E$. concordis e essa espécie, indicando que $E$. concordis não exerceu influência significativa sobre a densidade populacional desse tarsonemídeo (Tabela 3).

Para as outras espécies estudadas (P. citri, B. phoenicis, P. oleivora e Fungitarsonemus sp.) também foram observadas correlaçóes positivas e significativas $(r>0,45$; g.l. $=54$; $\mathrm{p} \leq 0,0005)$ para ácaros presentes em folhas e frutos, indicando movimentação significativa dos ácaros de folhas para frutos e vice-versa (Tabela 3). No caso de B. phoenicis, para o qual se observa nítida preferência por frutos (com $84,9 \%$ dos ácaros), a migração seria provavelmente mais intensa de folhas para frutos que o contrário. 
As correlações significativas observadas entre $E$. concordis e os ácaros fitófagos $P$. citri, B. phoenicis e P. oleivora, indicam que o predador exerce controle biológico sobre essas três espécies de ácaros-praga. Considerando-se que E. concordis foi a espécie de ácaro predador predominante (98,3\% dos fitoseídeos) no pomar cítrico estudado, pode-se inferir que houve pouca influência de outros ácaros predadores sobre as interaçóes entre esse inimigo natural e os ácaros fitófagos, dando maior confiabilidade às afirmaçôes sobre o efeito do fitoseídeo no controle dos ácaros-praga no pomar estudado.

No caso de B. phoenicis, alguns estudos em laboratório sobre capacidade de predaçáo de $E$. concordis sobre o ácaro-praga confirmam a atuação do predador como agente de controle dessa espécie. No entanto, ainda há necessidade de estudos complementares sobre predação e preferência alimentar, principalmente para P. citri e P. oleivora, para confirmar os resultados observados nesse trabalho.

\section{CONCLUSÃO}

As espécies de ácaros mais abundantes em pomar cítrico de Descalvado são Phyllocoptruta oleivora, Panonychus citri, Brevipalpus phoenicis e Fungitarsonemus sp. A espécie predominante de ácaro predador é Euseius concordis.

Há correlaçóes significativas entre as densidades populacionais de E. concordis e dos ácaros fitófagos $P$. citri, B. phoenicis e P. oleivora.

\section{AGRADECIMENTOS}

À FAPESP (Fundação de Apoio à Pesquisa do Estado de São Paulo), pelo suporte financeiro desta pesquisa (Processo: 2008/52691-9) e pela concessão da bolsa de Pós-Doutorado a Marcos Zatti da Silva (Processo: 2009/08789-7); ao CNPq pela concessão de bolsas.

\section{REFERÊNCIAS}

ALBUQUERQUE, F.A.; MORAES, G.J. Perspectivas para a criação massal de Iphiseiodes zuluagai Denmark \& Muma (Acari: Phytoseiidae). Neotropical Entomology, v.37, p.328-333, 2008.

AMRINE, J.R.; MANSON, D.C.M. Preparation, mounting and descriptive study of eriophyoid mites. In: LINDQUIST, E.E.; SABELIS, M.W.; BRUIN, J. (Ed.). World crop pests: eriophyoid mites: their biology, natural enemies and control. Amsterdam: Elsevier, 1996. p.383-396.

AYRES, M.; AYRES JUNIOR., M.; AYRES, D.L.; SANTOS, A.A.S. BioEstat 5.0. Aplicações estatísticas nas áreas das ciências biomédicas. Belém: Sociedade Civil Mamirauá/CNPq, 2007. 324p.
CLEMENTS, D.R.; HARMSEN, R. Stigmeid-phytoseiid interactions and the impact of natural enemy complexes on plantinhabiting mites. Experimental and Applied Acarology, v.14, p.327-341, 1992.

CROFT, B.A.; BLACKWOOD, J.S.; McMURTRY, J.A. Classifying life-style types of phytoseiid mites: diagnostic traits. Experimental and Applied Acarology, v.33, p.247-260, 2004.

FADAMIRO, H.Y.; XIAO, Y.; NESBITT, M.; CHILDERS, C.C. Diversity and Seasonal abundance of predacious mites in Alabama Satsuma citrus. Annals of the Entomological Society of America, v.102, p.617-628, 2009.

FLECHTMANN, C.H.W. Ácaros de importância agrícola. São Paulo: Nobel, 1989. 189p.

GRAFTON-CARDWELL, E.E.; OUYANG, Y. Influence of citrus leaf nutrition on survivorship, sex ratio, and reproduction of Euseius tularensis (Acari: Phytoseiidae). Environmental Entomology, v.25, p.1020-1025, 1996.

GRAVENA, S.; PAIVA, P.E.B.; SILVA, J.L.; BENVENGA, S.R.; GRAVENA, R.; ARAUJO JUNIOR, N. Ácaros dos citros. 2.ed. Jaboticabal: Gravena, 1999. 17p.

HELLE, W.; SABELIS, M.W. (Ed.). Spider mites: their biology, natural enemies and control. Amsterdam: Elsevier, 1985. v.1, 458p.

MacRAE, I.V.; CROFT, B.A. Differential impact of egg predation by Zetzellia mali (Acari: Stigmeidae) on Metaseiulus occidentalis and Typhlodromus pyri (Acari: Phytoseiidae). Experimental and Applied Acarology, v.20, p.143-154, 1996.

MATIOLI, A.L.; UECKERMANN, E.A.; OLIVEIRA, C.A.L. Some stigmaeid and eupalopsellid mites from citrus orchards in São Paulo State, Brazil (Acari: Stigmaeidae: Eupalopsellidae). International Journal of Acarology, v.28, p.109-120, 2002.

McCOY, C.W.; SELHIME, A.G.; KANAVEL, R.F. The feeding behavior and biology of Parapronematus acaciae (Acarina: Tydeidae). Florida Entomologist, v.52, p.13-19, 1969.

McMURTRY, J.A.; CROFT, B.A. Life styles of phytoseiid mites and their roles as biological control agents. Annual Review of Entomology, v.42, p.291-321, 1997.

MINEIRO, J.L.C.; SATO, M.E.; RAGA, A.; ARTHUR, V. Population dynamics of phytophagous and predaceous mites on coffee in Brazil, with emphasis on Brevipalpus phoenicis (Acari: Tenuipalpidae). Experimental and Applied Acarology, v.44, p.277-291, 2008.

MINEIRO, J.L.C.; RAGA, A.; SATO, M.E.; MATIOLI, A.L.; BERTON, L.H.C. Ácaros de cafeeiro (Coffea spp.) no Estado de São Paulo, Brasil. Parte II. Prostigmata. Biota Neotropica, v.10, 2010. Disponível em: http://www.biotaneotropica.org.br/v10n4/ pt/abstract?article+bn040. Acesso em 10/4/2010.

MORAES, G.J. Perspectivas para o uso de predadores no controle de ácaros fitófagos no Brasil. Pesquisa Agropecuária Brasileira, v.27, p.263-270, 1992. 
MORAES, G.J.; FLECHTMANN, C.H.W. Manual de Acarologia - Acarologia básica e ácaros de plantas cultivadas no Brasil. Ribeirão Preto: Holos, 2008. 308p.

OLIVEIRA, C.A.L. Flutuação populacional e medidas de controle do ácaro Brevipalpus phoenicis em citros. Laranja, v.6, p.1-32, 1986.

RAGA, A.; SATO, M.E.; CERÁVOLO, L.C.; ROSSI, A.C. Distribuição de ácaros predadores (Phytoseiidae) em laranjeira (Citrus sinensis L. Osbeck). Ecossistema, v.21, p.23-25, 1996.

REIS, P.R.; CHIAVEGATO, L.G. ALVES, E.B. SOUSA, E.Q. Ácaros da família Phytoseiidae associados aos citros no município de Lavras, sul de Minas Gerais. Anais da Sociedade Entomológica do Brasil, v.29, p.95-104, 2000.

RODRIGUES, J.C.V.; KITAJIMA, E.W.; CHILDERS, C.C.; CHAGAS, C.M. Citrus leprosis vírus vectored by Brevipalpus phoenicis (Acari: Tenuipalpidae) on citrus in Brazil. Experimental and Applied Acarology, v.30, p.161-179, 2003.

SATO, M.E.; RAGA, A.; CERÁVOLO, L.C.; ROSSI, A.C.; POTENZA, M.R. Ácaros predadores em pomar cítrico de
Presidente Prudente, Estado de São Paulo. Anais da Sociedade Entomológica do Brasil, v.23, p.435-441, 1994.

SATO, M.E.; RAGA, A.; CERÁVOLO, L.C.; SOUZA FILHO, M.F.; ROSSI, A.C.; MORAES, G.J. Effect of insecticides and fungicides on the interaction between members of the mite families Phytoseiidae and Stigmaeidae on citrus. Experimental and Applied Acarology, v.25, p.809-818, 2001.

SILVA, M.Z.; OLIVEIRA, C.A.L.; SATO, M.E. Seletividade de produtos fitossanitários sobre o ácaro predador Agistemus brasiliensis Matioli, Ueckermann \& Oliveira (Acari: Stigmaeidae). Revista Brasileira de Fruticultura, v.31, p.388396, 2009.

SPONGOSKI, S.; REIS, P.R.; ZACARIAS, M.S. Acarofauna da cafeicultura de cerrado em Patrocínio, Minas Gerais. Ciência e Agrotecnologia, v.29, p.9-17, 2005.

YANINEK, J.S.; MORAES, G.J. A synopsis of classical biological control of mites in agriculture. In: DUSBABEK, F.; BUKVA, V. (Ed.). Modern Acarology. Prague: Academia. The Hague: SPB Academic Publishing, 1991. p.133-149. 